\section{OPEN ACCESS}

Edited by:

Hsiao-Chi Chuang,

Taipei Medical University, Taiwan

Reviewed by:

James Hull,

Royal Brompton Hospital,

United Kingdom

Michael Furian,

University Hospital Zurich, Switzerland

*Correspondence:

Denis E. O'Donnell

odonnell@queensu.ca

Specialty section:

This article was submitted to

Pulmonary Medicine,

a section of the journal

Frontiers in Medicine

Received: 20 April 2020

Accepted: 31 July 2020

Published: 10 September 2020

Citation:

Milne KM, Domnik NJ, Phillips DB, James MD, Vincent SG, Neder JA and

O'Donnell DE (2020) Evaluation of

Dynamic Respiratory Mechanical

Abnormalities During Conventional

CPET. Front. Med. 7:548.

doi: $10.3389 /$ fmed.2020.00548

\title{
Evaluation of Dynamic Respiratory Mechanical Abnormalities During Conventional CPET
}

\begin{abstract}
Kathryn M. Milne ${ }^{1,2}$, Nicolle J. Domnik ${ }^{1}$, Devin B. Phillips ${ }^{1}$, Matthew D. James ${ }^{1}$, Sandra G. Vincent ${ }^{1}$, J. Alberto Neder ${ }^{3}$ and Denis E. O'Donnell ${ }^{1 *}$
\end{abstract}

${ }^{1}$ Respiratory Investigation Unit, Division of Respirology, Department of Medicine, Kingston Health Sciences Centre \& Queen's University, Kingston, ON, Canada, ${ }^{2}$ Clinician Investigator Program, Department of Medicine, University of British Columbia, Vancouver, BC, Canada, ${ }^{3}$ Laboratory of Clinical Exercise Physiology, Division of Respirology, Department of Medicine, Kingston Health Sciences Centre \& Queen's University, Kingston, ON, Canada

Assessment of the ventilatory response to exercise is important in evaluating mechanisms of dyspnea and exercise intolerance in chronic cardiopulmonary diseases. The characteristic mechanical derangements that occur during exercise in chronic respiratory conditions have previously been determined in seminal studies using esophageal catheter pressure-derived measurements. In this brief review, we examine the emerging role and clinical utility of conventional assessment of dynamic respiratory mechanics during exercise testing. Thus, we provide a physiologic rationale for measuring operating lung volumes, breathing pattern, and flow-volume loops during exercise. We consider standardization of inspiratory capacity-derived measurements and their practical implementation in clinical laboratories. We examine the evidence that this iterative approach allows greater refinement in evaluation of ventilatory limitation during exercise than traditional assessments of breathing reserve. We appraise the available data on the reproducibility and responsiveness of this methodology. In particular, we review inspiratory capacity measurement and derived operating lung volumes during exercise. We demonstrate, using recent published data, how systematic evaluation of dynamic mechanical constraints, together with breathing pattern analysis, can provide valuable insights into the nature and extent of physiological impairment contributing to exercise intolerance in individuals with common chronic obstructive and restrictive respiratory disorders.

Keywords: respiratory physiology, dyspnea, respiratory mechanics, inspiratory capacity, cardiopulmonary exercise test

\section{INTRODUCTION}

Assessment of the ventilatory response to exercise is important in evaluating mechanisms of dyspnea and exercise intolerance in cardiopulmonary diseases (1). The value of the information obtained during cardiopulmonary exercise tests (CPETs) is dependent on the degree to which physiological processes are accurately represented; the quality, reliability, and responsiveness of the measurements; and the interpretation of data to meaningfully impact clinical care. The insights provided by invasive respiratory mechanics using esophageal catheter techniques inform an understanding of respiratory system function during exercise. Although employed in research 
settings for assessment of respiratory mechanics, during clinical CPETs, esophageal catheter insertion can be cumbersome and time-consuming. Simple, low-cost, non-invasive methods to assess respiratory mechanics in the clinical setting are therefore needed and are the focus of the current review.

Ventilatory limitation is traditionally measured as the ratio of ventilation $\left(\mathrm{V}_{\mathrm{E}}\right)$ at peak exercise to measured or estimated maximal voluntary ventilation $\left(\mathrm{V}_{\mathrm{E}} / \mathrm{MVV}\right)$, with a ratio $>85 \%$ used to identify ventilation as the cause of reduced exercise capacity (1). Measured MVV during hyperpnea at rest differs from peak exercise $V_{E}$ in respiratory muscle recruitment, operating lung volumes, and breathing pattern (2). Additionally, a high $\mathrm{V}_{\mathrm{E}} / \mathrm{MVV}$ provides little information about the specific factors limiting the ventilatory response to exercise in the individual. Patients may perceive intolerable dyspnea during exercise before criteria defining ventilatory limitation are reached. In chronic obstructive pulmonary disease (COPD), $20-50 \%$ of patients experience exercise-limiting dyspnea in the setting of sufficient breathing reserve $(3,4)$. Relying solely on breathing reserve to assess ventilatory response may therefore underestimate physiologic impairment. Measurement of operating lung volumes including end-inspiratory lung volume (EILV), end-expiratory lung volume (EELV), and inspiratory reserve volume (IRV) can be derived from inspiratory capacity (IC) and tidal volume $\left(\mathrm{V}_{\mathrm{T}}\right)$ measurement throughout exercise in combination with resting total lung capacity (TLC) $\left(\mathrm{EILV}=\mathrm{EELV}+\mathrm{V}_{\mathrm{T}}, \mathrm{EELV}=\mathrm{TLC}-\mathrm{IC}\right.$, and IRV $\left.=\mathrm{IC}-\mathrm{V}_{\mathrm{T}}\right)$. Exercise flow-volume loops (FVLs) can provide complementary qualitative assessment of airflow limitation (5). Analysis of operating lung volumes, FVLs, and breathing pattern provides insight into mechanical constraints contributing to exercise limitation and dyspnea, avoiding sole reliance on breathing reserve to define ventilatory limitation (5).

Our objective is to provide a brief synopsis of characteristic respiratory mechanical responses to exercise, important assumptions, and limitations involved in measuring operating lung volumes using conventional IC maneuvers, and the rationale for these measurements as they apply to clinical CPET for the frontline clinician. We briefly review recommendations and resources for IC maneuver measurement and available evidence for reliability and reproducibility as well as present a rationale for interpreting operating lung volumes. Finally, we comment on the responsiveness of these dynamic measurements to therapeutic interventions. Other non-invasive methods of assessing respiratory mechanics (e.g., gas dilution techniques and optoelectronic plethysmography) are beyond the scope of this mini-review targeted for clinicians. We direct the interested reader to other recently published reviews on this topic $(3,4)$.

\section{RESPIRATORY MECHANICS IN HEALTH AND DISEASE}

\section{Dynamic Respiratory Mechanics in Health}

In health, $V_{E}$ increases in response to the metabolic demands of exercise by increases in $\mathrm{V}_{\mathrm{T}}$ and breathing frequency $\left(f_{\mathrm{B}}\right)$. $\mathrm{V}_{\mathrm{T}}$ expansion reaches an inflection point at $50-60 \%$ of the resting vital capacity (VC), and subsequent rises in $\mathrm{V}_{\mathrm{E}}$ are secondary to increased $f_{\mathrm{B}}$ (Figures 1C,D) (6). In young individuals $(<35$ years old), $\mathrm{V}_{\mathrm{T}}$ expands with an increase in EILV and decrease in EELV (Figure 2A) (7). In contrast to passive expiration at rest, recruitment of expiratory muscles during exercise leads to a decrease in EELV. This permits $\mathrm{V}_{\mathrm{T}}$ to expand within the linear compliant portion of the respiratory system pressure-volume curve (Figure 2A). This delays the point during exercise when IRV reaches its lowest value (i.e., EILV is $90-95 \%$ of TLC), and the inspiratory muscles must contend with increased elastic mechanical loading (Figure 1B) $(8,9)$.

FVLs collected during exercise provide a visual representation of $\mathrm{V}_{\mathrm{T}}$ expansion relative to available capacity. Expiratory flow limitation (EFL) is dependent on the adopted breathing pattern, dynamic EILV and EELV, and maximum FVL (5). EFL can be qualitatively assessed as the percentage of $V_{T}$ over which expiratory airflow is superimposed on or exceeds the maximal flow-volume envelope (Figure 1E) (5). With this approach, establishing an accurate maximal FVL is essential, and without accounting for the influence of thoracic gas compression during forced maneuvers and exercise induced changes in airway caliber overestimation of EFL may result (14). Assessment of maximal FVLs before and after exercise is therefore important. Concavity of the FVL expiratory limb has been associated with dynamic hyperinflation (DH) in severe COPD (15). EFL can be quantitatively assessed using negative expiratory pressure, where application of a standardized negative pressure during expiration and assessment of corresponding changes in expiratory flow are used to determine flow limitation (16-18).

Changes of the respiratory system in healthy aging ( $>70$ years old) have previously been reviewed and include increased lung compliance, decreased chest wall compliance, increased EFL, and elevated ventilatory demand (19). During exercise, EFL occurs at lower $\mathrm{V}_{\mathrm{E}}$, and both EFL and increased EELV above resting values are more frequently observed at peak exercise in older individuals compared to young adults (20-23). The differences in exertional breathlessness observed in older adults are at least in part related to increased awareness of $\mathrm{V}_{\mathrm{E}}$ and changes in respiratory mechanical responses during exercise (23-26).

\section{Dynamic Respiratory Mechanics in Chronic Lung Disease}

\section{Defining Critical Respiratory Mechanical Constraints}

In chronic lung disease, pathology of the lung parenchyma, chest wall, airways, and pulmonary vasculature alter respiratory system compliance, airway resistance, and pulmonary gas exchange, which in variable combination have a deleterious impact on exercise capacity (see reviews in this issue by Devin Phillips, "Measurement and interpretation of ventilatory efficiency during exercise," and by Denis O’Donnell, “An integrative approach to clinical CPET interpretation"). Increased exertional dyspnea intensity in chronic lung disease is closely related to increased magnitude of inspiratory neural drive (IND) (11) (see review in this issue by Matthew James, "Dyspnea and exercise limitation in COPD: the value of CPET"). Respiratory sensation becomes increasingly unpleasant as 


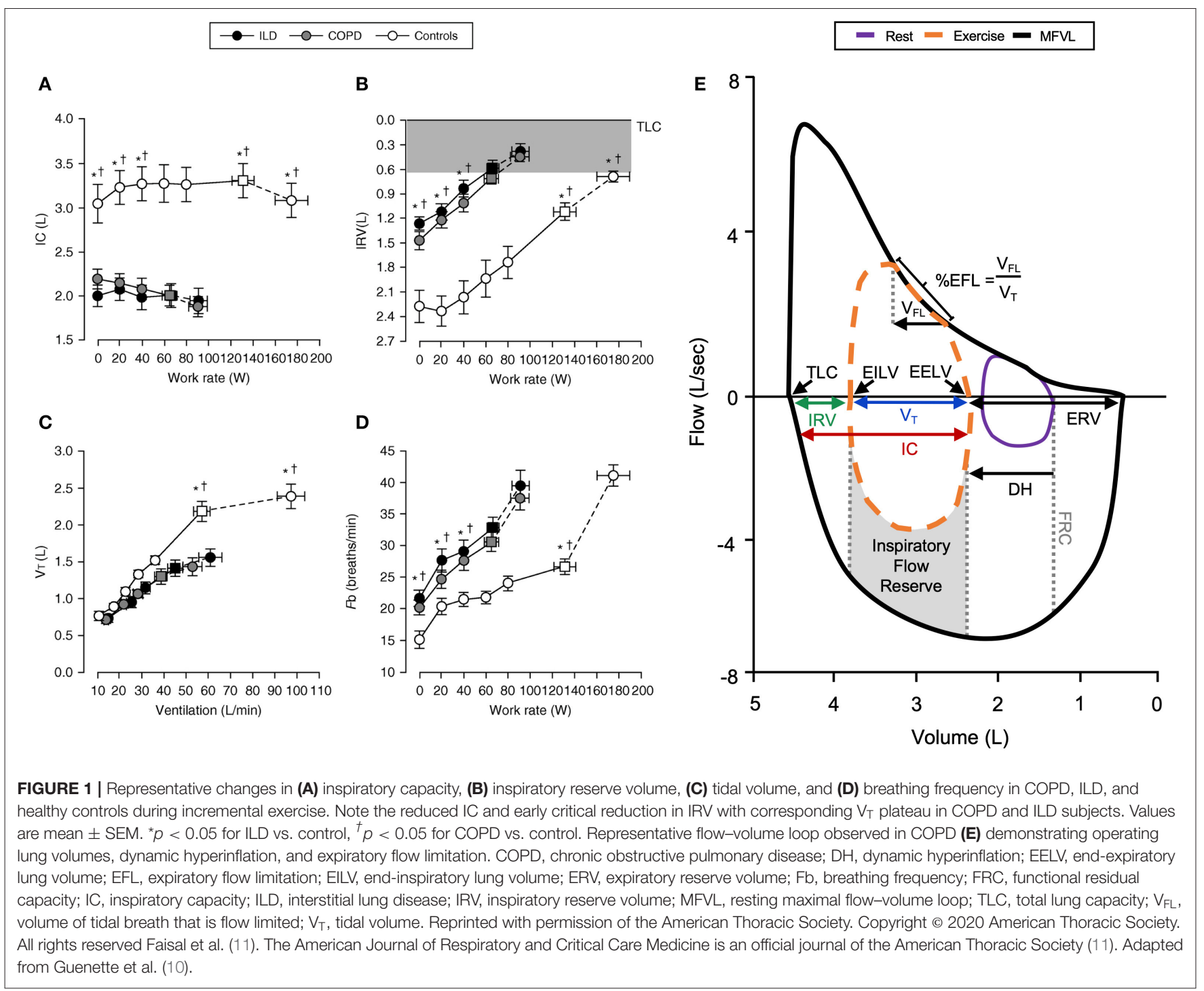

neuromechanical dissociation develops, marking the point where increased IND is met with reduced ability of the respiratory system to match increased demand (27). Development of critical respiratory mechanical constraint is defined by the point at which IRV is reduced (within $0.5-1 \mathrm{~L}$ of TLC and EILV/TLC > 90-95\%), $\mathrm{V}_{\mathrm{T}}$ expansion has reached an inflection or plateau (occurring at $\mathrm{V}_{\mathrm{T}} / \mathrm{IC} \sim 70 \%$, identified when $V_{T}$ is plotted against $V_{E}$ ), and a pronounced increase in dyspnea severity and alteration in its quality (i.e., onset of "unsatisfied inspiration") occurs (6, 28-30). Importantly, in combination with measures of ventilatory inefficiency, critical mechanical constraints are a more robust predictor of exertional dyspnea and peak $\mathrm{VO}_{2}$ compared with breathing reserve (31).

\section{Dynamic Respiratory Mechanics in COPD}

In COPD, increased lung compliance and EFL due to emphysematous parenchymal destruction and airway remodeling increase the heterogeneity of mechanical time constants for lung emptying. Under the stress of exercise, in the setting of EFL and increased $V_{E}$, there is insufficient time for complete lung emptying, and normal reduction of EELV is impaired (Figures 1E,2B) (32). Progressive increase in EELV during exercise (i.e., $\mathrm{DH}$ ) undermines the optimal positioning of $\mathrm{V}_{\mathrm{T}}$ on the pressure-volume curve of the respiratory system (Figure $2 \mathbf{B}$ ), and dynamic lung compliance decreases while EELV increases in the setting of stable TLC $(11,32,33)$. Progressive reduction of IC and IRV during exercise indirectly reflects increased intrinsic elastic mechanical loading of the inspiratory muscles. In flow-limited patients, the IC represents the operating limits for $\mathrm{V}_{\mathrm{T}}$ expansion during exercise $(30,34,35)$. Thus, as IC is reduced, compensatory tachypnea is the only means to increase $\mathrm{V}_{\mathrm{E}}$ (Figure 1D). Identification of the $\mathrm{V}_{\mathrm{T}}$ inflection or plateau plotted against $\mathrm{V}_{\mathrm{E}}$ (Figure 1C) corresponds with the point where IRV reaches a critical minimal (Figure 1B) value in the face of increasing IND. 


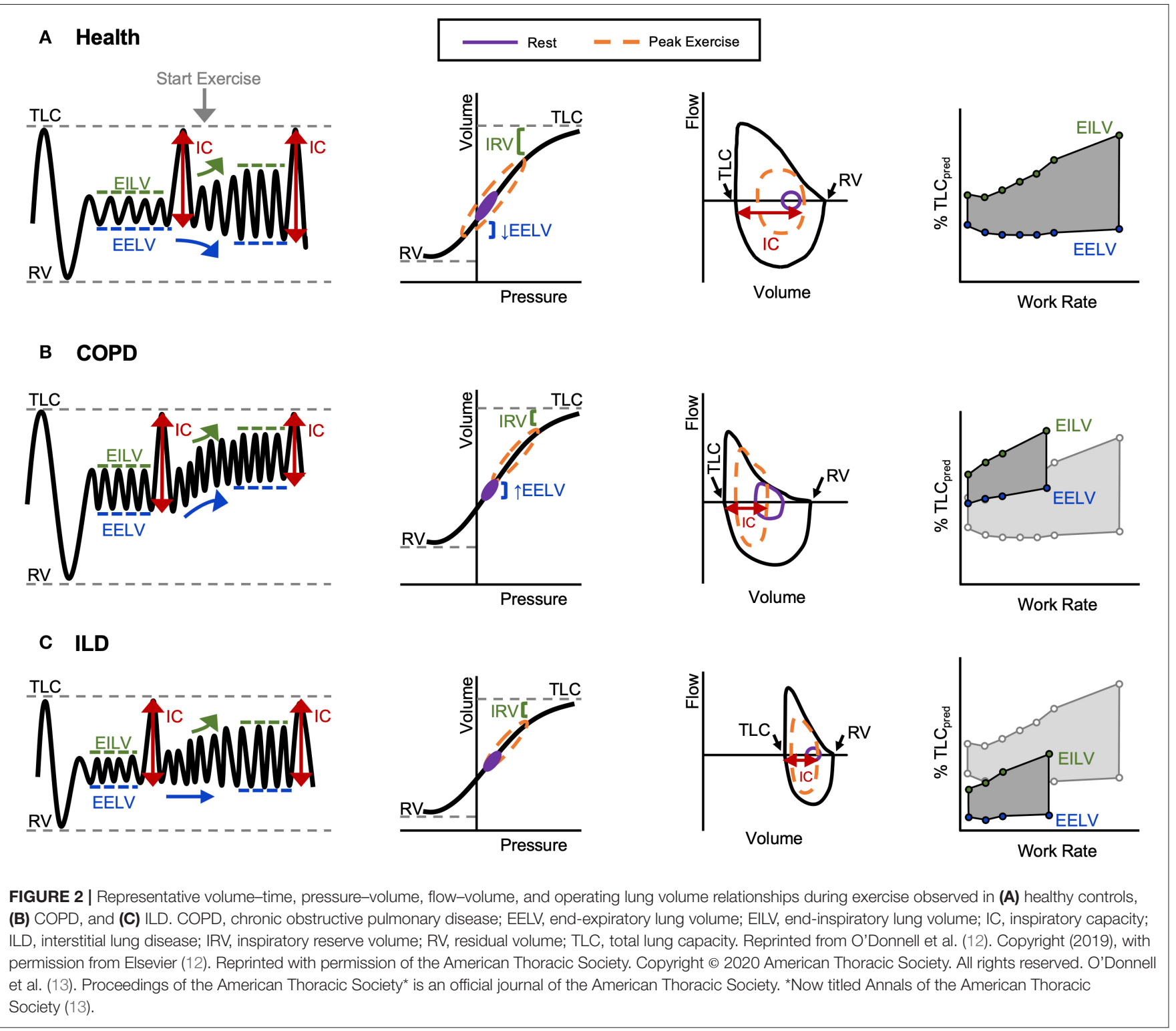

Dynamic respiratory mechanical constraints not only strongly influence the adopted breathing pattern but are also key to the development of exertional dyspnea leading to reduced exercise capacity $(30,36-42)$.

\section{Dynamic Respiratory Mechanics in ILD}

In ILD, lung compliance, TLC, and IRV are all reduced, and $\mathrm{V}_{\mathrm{T}}$ expansion is constrained during exercise reflecting a low IC (11, 43). As a result, critical reduction in IRV manifests early during exercise, and $\mathrm{V}_{\mathrm{T}}$ is positioned close to the reduced TLC and upper extreme of the contracted pressure-volume curve (Figure 2C). In ILD patients with airway involvement, $\mathrm{V}_{\mathrm{T}}$ expansion may additionally be restricted due to EFL and an increase in EELV (44, 45). Importantly, in these examples, the classically observed rapid shallow breathing pattern (Figures 1C,D) is a response to the reduced compliance of the respiratory system resulting from restriction of IC and IRV (Figures 1A,B). In both obstructive (COPD) and restrictive (ILD) diseases, "high-end" dynamic mechanics with increased elastic loading, restriction of $\mathrm{V}_{\mathrm{T}}$ expansion, and relative tachypnea together contribute to functional respiratory muscle weakness, increased work of breathing, IND, and dyspnea (11).

\section{Dynamic Respiratory Mechanics in Other Chronic Lung Diseases}

Beyond the examples of COPD and ILD, changes in operating lung volumes during exercise have been observed in obesity (46), cystic fibrosis (47), and pulmonary arterial hypertension (PAH) (48). However, unlike healthy, COPD, and ILD populations, the assumptions underpinning IC-derived measurements outlined in the following section have not as yet been robustly investigated in these populations. 


\section{KEY ASSUMPTIONS AND LIMITATIONS OF IC-DERIVED OPERATING LUNG VOLUMES}

\section{Validity}

IC-derived measurements have been shown to be a valid representation of respiratory mechanics during exercise when performed in conjunction with invasive evaluations using esophageal manometry $(29,49,50)$. This has been most thoroughly assessed in COPD patients, and validation of ICderived techniques in diverse patient populations is needed. IC is determined by the degree of lung hyperinflation and inspiratory muscle strength. Determination of changes in operating lung volumes assumes that changes in IC represent inverse changes in EELV during exercise. Thus, TLC and static inspiratory muscle strength at end-exercise must be similar to values generated at rest for reliable results $(7,33,49)$. Stability of TLC during exercise has been demonstrated in healthy, COPD, and ILD populations $(33,45,46)$. Furthermore, esophageal pressure (Pes) measured at peak inspired volume plateau (Pes at zero flow following IC) is stable during incremental CPET performed to symptom limitation in COPD (49). When expressed as a percentage of Pes during IC at rest, Pes at symptom limited peak exercise IC exceeds $90 \%$ of resting values (49). Additionally, preservation of inspiratory muscle strength assessed using maximal inspiratory pressure (MIP) and sniff Pes pre- and post-exercise demonstrates that respiratory muscle strength can be maintained during exercise $(29,37,38,40,42,50-53)$. Taken together, stability of TLC and preservation of Pes-derived assessment of respiratory muscle strength pre- and post-exercise as well as dynamically during exercise IC maneuvers provides evidence that changes in IC reflect changes in operating lung volumes.

\section{Potential Limitations}

Reliable IC-derived measurements additionally assume that maximal volitional effort results in maximal diaphragm activation. The diaphragm has been demonstrated to be maximally activated during voluntary effort in patients with COPD (54). Although maximal voluntary activation of the diaphragm is possible, reproducibility is challenging (55). A recently published study by Luo et al. demonstrated that in some severe COPD patients, IC measurements and associated diaphragm activation (assessed using diaphragmatic electromyography) were submaximal in comparison to supraphysiological experimental stimulation (inhaled $8 \%$ $\mathrm{CO}_{2}$ gas mixture) (56). Assessing reproducible maximal volitional effort during IC maneuvers can be challenging in the clinical setting, and if patients are not able to perform reproducible IC maneuvers at rest, exercise measurements should not be performed.

Stability of TLC, preservation of maximal voluntary Pes during IC maneuvers, and the voluntary ability to maximally activate the diaphragm support the rationale for using IC maneuvers to measure operating lung volumes. Important clinical scenarios that limit the validity of ICderived measurements to assess respiratory mechanics include respiratory muscle weakness (failure to successfully reach TLC during IC maneuver can lead to erroneous conclusion of $\mathrm{DH}$ ), leak during IC maneuver (inability to maintain mouthpiece seal, e.g., bulbar muscle weakness), and inability of the patient to perform reproducible resting IC maneuvers. Additionally, IC-derived measurement of operating lung volumes cannot assess the contribution of chest wall mechanics directly during exercise, and added dead space of mouthpieces may influence breathing patterns. Clinicians should be alert to these situations and consider employing alternative tools for assessment of respiratory mechanics to avoid unreliable operating lung volume measurements.

\section{PERFORMING HIGH-QUALITY REPRODUCIBLE IC MEASUREMENTS}

\section{Quality Assessment}

To obtain reliable and reproducible measurements, IC maneuvers should be performed using a standardized approach. Factors that can interfere with the quality of IC measurements include insufficient instruction, inadequate number of premaneuver tidal breaths for assessment of EELV, unstable EELV due to anticipatory changes in breathing patterns, and inadequate effort (10). Quality control considerations, procedures for IC maneuvers, and strategies for ensuring a stable EELV prior to IC measurement are summarized in Table $1(10,53)$. Interested readers are directed to a review by Guenette et al. that describes IC procedures and instructions in detail (10). International guidelines recommend that at least three acceptable resting IC maneuvers be performed and that the mean value of all acceptable resting IC maneuvers be reported $(57,58)$. IC measurement can be performed during constant work rate (CWR) (59-61) and incremental (62) CPET during both treadmill and cycle exercises (36, 63, 64). During incremental CPET, stepwise increases in work rate as opposed to ramp protocols are preferred so that $\mathrm{V}_{\mathrm{E}}$ reaches relative stability during each incremental stage when an IC maneuver is performed (10).

\section{Reproducibility}

IC measurements at rest, submaximal, and peak exercise are highly reproducible over time $(34,53,65,66)$. Within-subject coefficient of variation for IC during exercise is $12-20 \%$ and has been reported to be higher at end-exercise $(34,65,66)$. During CWR CPET performed in a multicenter clinical trial of patients with moderate to severe COPD, IC values at rest, iso-time, and end-exercise are highly repeatable between visits (intraclass correlation $R \geq 0.87)(66,67)$.

\section{INTERPRETATION OF OPERATING LUNG VOLUMES}

Operating lung volumes can be plotted vs. work rate, oxygen consumption $\left(\mathrm{VO}_{2}\right)$, or $\mathrm{V}_{\mathrm{E}}$ during exercise $(14,30,34)$. Concurrent displays of breathing pattern and FVLs add further refinement to the evaluation of dynamic mechanics. Operating lung volumes should preferably be shown with values derived from healthy age- and sex-matched controls from the same 
TABLE 1 | Key steps in IC maneuver performance during CPET.

\begin{tabular}{ll}
\hline $\begin{array}{l}\text { Prior to IC } \\
\text { assessment }\end{array}$ & $\begin{array}{l}\text { Technical } \\
\text { considerations }\end{array}$ \\
& \\
& $\begin{array}{l}\text { Clinical } \\
\text { considerations }\end{array}$ \\
& \\
Resting IC & Preparation and \\
assessment & instructions
\end{tabular}

assessment instructions

Quality

assessment

Dynamic IC

Preparation and

assessment instructions

Quality

assessment
- Use of bidirectional flow-sensing devices for integrated calculation of volume. Measurement of inspiratory and expiratory volumes is important for assessment of EELV and breathing pattern during IC maneuvers $(10,57,65)$.

- Breath-by-breath cardiopulmonary exercise metabolic system that accounts for thermodynamic drift $(5,65)$.

- The technician conducting the exercise test should be able to view volume-time and/or flow-volume loop tracings preceding and during IC maneuvers.

- Review presence of illness that may impact reliability of IC-derived operating lung volumes during exercise (e.g., respiratory muscle weakness and bulbar muscle weakness).

- Consider need for alternative or invasive assessment of respiratory mechanics in patients in whom IC-derived measurements may not be reliable.

1. General description of IC maneuver: "During the resting period and during each stage of exercise, you will be asked to take a deep breath in until your lungs are completely full. To do this, you will finish your normal breath out then fill up your lungs quickly until you are all the way full. When you can't get any more air in and are completely full, then you can go back to normal breathing" (10).

2. Demonstration of IC maneuver by technician conducting the exercise test demonstrating normal stable breathing pattern followed by complete inhalation to TLC quickly and without hesitation during IC maneuver.

3. Review instructions for initiation of IC maneuver in order to obtain reproducible measurements at rest. Instructions may be tailored in response to anticipatory changes in breathing pattern by the patient as outlined below (66):

- "At the end of a normal breath out, take a deep breath all the way in until you are completely full" (10, 53). This instruction may be given when anticipatory changes in breathing pattern are not observed prior to IC maneuvers.

- "At the end of this next breath out, take a deep breath all the way in until you are completely full" (10, 53). This instruction may be helpful in patients who exhibit anticipatory changes prior to IC maneuvers.

- "Breath all the way in on this breath" (10). This instruction may be given when anticipatory changes in breathing pattern are not successfully overcome with other sets of instructions, review of the technique, and demonstration. Timing of providing this instruction can be challenging, particularly at high exercise intensities.

4. Repeat resting IC measurement following a minimum of $60 \mathrm{~s}$ and only after breathing pattern has returned to pre-maneuver baseline.

5. Verbal encouragement during IC maneuvers to encourage patients to maximally inhale to TLC may be given; however, during research studies, it is particularly important for encouragement to be standardized.

- Acceptable IC measurement must not include cough, swallowing, evidence of an obstructed mouthpiece, or mouthpiece leak in the tidal breaths preceding or during the IC maneuver (57).

- See Dynamic IC assessment below re: EELV.

- Although current guidelines do not include reproducibility criteria for resting IC maneuvers (57), values within $10 \%$ of the largest acceptable value are frequently used as a threshold for reproducibility (66).

- The mean of acceptable values should be reported (57).

- Provide instructions for collection of peak exercise IC prior to commencing exercise test: "During this exercise test the goal is for you to exercise as long as you can until you feel you can't exercise any longer. When you feel you have 10-15s left, give us a warning wave with your hand so that we can collect the final breathing maneuver" (10).

- EELV assessment prior to IC maneuvers should include a minimum of four tidal breaths (10).

- Breathing pattern (depth, frequency, and timing) and EELV should be stable prior to each IC maneuver $(10,65)$. Anticipatory changes in breathing pattern prior to IC maneuvers can frequently be overcome with adjustment of instructions during preparation at rest, see Resting IC assessment above.

- EELV during expiration immediately prior to an IC maneuver may frequently overestimate or underestimate EELV, and in this case, the mean EELV for the breaths preceding the IC prompt should be used $(65,66)$.

- Variability in EELV may reflect a mouthpiece leak, and patients should be reminded to maintain a seal on the mouthpiece.

- IC measurements following unstable EELV should be discarded. Generally, during dynamic IC measurement, IC maneuvers are not repeated until the next planned interval.

- Peak exercise IC during a CPET performed to symptom limitation should be obtained immediately prior to exercise cessation (10).

CPET, cardiopulmonary exercise test; EELV, end-expiratory lung volume; IC, inspiratory capacity; TLC, total lung capacity.

laboratory. When health and disease are compared, expressing values as a percentage of predicted TLC is appropriate, especially when disease alters TLC (10). When reporting individual data, expressing volumes in absolute values or as a percentage of measured TLC may be preferred (10). FVL analysis provides qualitative estimation of EFL and graphic displays of change in operating lung volumes when tidal FVLs are carefully placed on the absolute lung volume axis using serial IC maneuvers and resting TLC (5).

The methodology for describing operating lung volume behavior during exercise is most extensively described in COPD. Change in IC from rest to end-exercise is an accepted assessment of DH (34). An absolute volume threshold to define DH has been debated in the literature. The limitations of an absolute volume 
definition potentially neglect the importance of interpreting any change in EELV as it relates to development of critical respiratory mechanical constraints, symptoms, and exercise intolerance. Change in IC during exercise should be interpreted in the context of the resting baseline value and critical reduction in IRV during exercise. The advantage of interpreting operating lung volumes and breathing pattern variables together during CPET is the ability to assess the integrated physiologic response to a standardized exercise task. Slopes of IC over time, $\mathrm{VO}_{2}$, or $\mathrm{V}_{\mathrm{E}}$ provide insight into submaximal changes in respiratory mechanics but may not follow a linear relationship (34). In studies comparing effects of bronchodilators with placebo, it is important to additionally assess whether the slope of IC throughout exercise was reduced (i.e., reduced rate of $\mathrm{DH}$ ) or whether the slope is unchanged but is shifted downward in parallel to placebo, as often is the case. Both a reduced rate of DH and downward shift of EELV and EILV following bronchodilator therapy will delay onset of critical respiratory mechanical constraints, dyspnea, and allow for a longer exercise endurance time.

\section{OPERATING LUNG VOLUME RESPONSIVENESS TO THERAPY}

In COPD, a low resting IC usually reflects lung hyperinflation, and as a result, $\mathrm{V}_{\mathrm{T}}$ expansion and increase in $\mathrm{V}_{\mathrm{E}}$ are limited from the outset of exercise. Resting IC values are correlated with peak $\mathrm{VO}_{2}$ (36). Furthermore, IC/TLC is related to mortality, acute exacerbation risk, and development of dyspnea in COPD $(30,68-71) . \mathrm{DH}$ is associated with increased mortality (72). Improvement in IC $>0.14 \mathrm{~L}$ (or $4.5 \%$ predicted) exceeds $95 \%$ confidence intervals and is associated with significant clinically meaningful improvements in exercise endurance time (36).

Significant improvement in operating lung volumes are highly correlated with reduced exertional dyspnea in COPD following treatment with bronchodilators (34, 59, 60, 73-83). Hyperoxia in both ILD and COPD, by reducing IND and breathing frequency, delays the onset of critical mechanical constraints and extends exercise endurance time $(36,43,84)$. In COPD, the effects of bronchodilators and oxygen are additive (85). Exercise training programs in COPD lead to a decrease in IND, $\mathrm{V}_{\mathrm{E}}$, and breathing frequency, thought to reflect a delay in metabolic acidosis in the subset of patients able to achieve physiologic training effects, in turn

\section{REFERENCES}

1. American Thoracic Society and American College of Chest Physicians. ATS/ACCP Statement on cardiopulmonary exercise testing. Am J Respir Crit Care Med. (2003) 167:211-77. doi: 10.1164/rccm.167.2.211

2. Klas JV, Dempsey JA. Voluntary versus reflex regulation of maximal exercise flow: volume loops. Am Rev Respir Dis. (1989) 139:150-6. doi: 10.1164/ajrccm/139.1.150

3. Massaroni C, Carraro E, Vianello A, Miccinilli S, Morrone M, Levai IK, et al. Optoelectronic plethysmography in clinical practice and research: a review. Respiration. (2017) 93:339-54. doi: 10.1159/000462916 delaying onset of ventilatory constraints (86-90). Pulmonary rehabilitation improves exercise capacity in ILD patients, and the ongoing multicenter HOPE-IPF study examines the combined effect of exercise training and oxygen (91-95). During exercise while breathing heliox $\left(21 \% \mathrm{O}_{2}\right.$ and $\left.79 \% \mathrm{He}\right)$ in COPD, a lower gas density of helium leads to decreased airflow resistance, $\mathrm{V}_{\mathrm{E}}$, and $\mathrm{DH}$ (96-98). Bullectomy and lung volume reduction surgery improve static lung elastic recoil, $\mathrm{DH}$, and respiratory muscle function in COPD (99-101). The impact of these interventions and the underlying mechanisms of improvement can be deduced by measuring dynamic respiratory mechanics.

\section{CONCLUSIONS}

Operating lung volumes measured throughout exercise provide an assessment of dynamic respiratory mechanics in the clinical setting. IC maneuvers during exercise are simple to perform and, provided sufficient attention is applied, are accurate and reproducible, providing important information about the cause of dyspnea and exercise limitation on an individual basis. Non-invasive measurement of operating lung volumes offers insight into the development of critical respiratory mechanical constraints during exercise, which have been shown to better predict $\mathrm{VO}_{2}$ and dyspnea than traditional indices of breathing reserve.

Widespread adoption of conventional IC-derived noninvasive mechanics assessment in clinical CPET awaits development of normative population ranges for operating lung volumes throughout exercise and assessment of reliability in diverse patient populations. Standardized methods for data display and quality control using commercial metabolic carts will facilitate integrating these important physiologic measurements in clinical CPET so as to advance individualized clinical evaluation and management of symptomatic patients.

\section{AUTHOR CONTRIBUTIONS}

DO'D conceived the idea for the manuscript. KM wrote the first draft of the manuscript. KM, ND, DP, MJ, SV, JN, and DO'D provided critical review and revision of the manuscript. All named authors meet the International Committee of Medical Journal Editors (ICMJE) criteria for authorship for this article. 
7. Stubbing DG, Pengelly LD, Morse JL, Jones NL. Pulmonary mechanics during exercise in normal males. J Appl Physiol Respir Environ Exerc Physiol. (1980) 49:506-10. doi: 10.1152/jappl.1980.49.3.506

8. Henke KG, Sharratt M, Pegelow D, Dempsey JA. Regulation of endexpiratory lung volume during exercise. J Appl Physiol. (1985) 64:135-46. doi: 10.1152/jappl.1988.64.1.135

9. Younes M, Kivinen G. Respiratory mechanics and breathing pattern during and following maximal exercise. J Appl Physiol Respir Environ Exerc Physiol. (1984) 57:1773-82. doi: 10.1152/jappl.1984.57.6.1773

10. Guenette JA, Chin RC, Cory JM, Webb KA, O’Donnell DE. Inspiratory capacity during exercise: measurement, analysis, and interpretation. Pulm Med. (2013) 2013:956081. doi: 10.1155/2013/956081

11. Faisal A, Alghamdi BJ, Ciavaglia CE, Elbehairy AF, Webb KA, Ora $\mathrm{J}$, et al. Common mechanisms of dyspnea in chronic interstitial and obstructive lung disorders. Am J Respir Crit Care Med. (2016) 193:299-309. doi: 10.1164/rccm.201504-0841OC

12. O'Donnell DE, Milne KM, Vincent SG, Neder JA. Unraveling the causes of unexplained dyspnea: the value of exercise testing. Clin Chest Med. (2019) 40:471-99. doi: 10.1016/j.ccm.2019.02.014

13. O'Donnell DE. Hyperinflation, dyspnea, and exercise intolerance in chronic obstructive pulmonary disease. Proc Am Thorac Soc. (2006) 3:180-4. doi: 10.1513/pats.200508-093DO

14. Guenette JA, Dominelli PB, Reeve SS, Durkin CM, Eves ND, Sheel AW. Effect of thoracic gas compression and bronchodilation on the assessment of expiratory flow limitation during exercise in healthy humans. Respir Physiol Neurobiol. (2010) 170:279-86. doi: 10.1016/j.resp.2010.01.017

15. Varga J, Casaburi R, Ma S, Hecht A, Hsia D, Somfay A, et al. Relation of concavity in the expiratory flow-volume loop to dynamic hyperinflation during exercise in COPD. Respir Physiol Neurobiol. (2016) 234:79-84. doi: 10.1016/j.resp.2016.08.005

16. Valta P, Corbeil C, Lavoie A, Campodonico R, Koulouris N, Chasse $\mathrm{M}$, et al. Detection of expiratory flow limitation during mechanical ventilation. Am J Respir Crit Care Med. (1994) 150(5 Pt 1):1311-7. doi: 10.1164/ajrccm.150.5.7952558

17. Koulouris NG, Valta P, Lavoie A, Corbeil C, Chasse M, Braidy J, et al. A simple method to detect expiratory flow limitation during spontaneous breathing. Eur Respir J. (1995) 8:306-13. doi: 10.1183/09031936.95.080 20306

18. Koulouris NG, Dimopoulou I, Valta P, Finkelstein R, Cosio MG, Milic-Emili J. Detection of expiratory flow limitation during exercise in COPD patients. J Appl Physiol. (1985) 82:723-31. doi: 10.1152/jappl.1997.82.3.723

19. Jensen D, Ofir D, O'Donnell DE. Effects of pregnancy, obesity and aging on the intensity of perceived breathlessness during exercise in healthy humans. Respir Physiol Neurobiol. (2009) 167:87-100. doi: 10.1016/j.resp.2009.01.011

20. Frank NR, Mead J, Ferris BG Jr. The mechanical behavior of the lungs in healthy elderly persons. J Clin Invest. (1957) 36:1680-7. doi: 10.1172/JCI103569

21. Johnson BD, Reddan WG, Pegelow DF, Seow KC, Dempsey JA. Flow limitation and regulation of functional residual capacity during exercise in a physically active aging population. Am Rev Respir Dis. (1991) 143(5 Pt 1):960-7. doi: 10.1164/ajrccm/143.5_Pt_1.960

22. Johnson BD, Reddan WG, Seow KC, Dempsey JA. Mechanical constraints on exercise hyperpnea in a fit aging population. Am Rev Respir Dis. (1991) 143(5 Pt 1):968-77. doi: 10.1164/ajrccm/143.5_Pt_1.968

23. Molgat-Seon Y, Dominelli PB, Ramsook AH, Schaeffer MR, Molgat Sereacki $\mathrm{S}$, Foster GE, et al. The effects of age and sex on mechanical ventilatory constraint and dyspnea during exercise in healthy humans. J Appl Physiol. (2018) 124:1092-106. doi: 10.1152/japplphysiol.00608.2017

24. DeLorey DS, Babb TG. Progressive mechanical ventilatory constraints with aging. Am J Respir Crit Care Med. (1999) 160:169-77. doi: $10.1164 /$ ajrccm.160.1.9807045

25. Killian KJ, Summers E, Jones NL, Campbell EJ. Dyspnea and leg effort during incremental cycle ergometry. Am Rev Respir Dis. (1992) 145:1339-45. doi: $10.1164 /$ ajrccm/145.6.1339

26. Ofir D, Laveneziana P, Webb KA, Lam YM, O’Donnell DE. Sex differences in the perceived intensity of breathlessness during exercise with advancing age. J Appl Physiol. (2008) 104:1583-93. doi: 10.1152/japplphysiol.00079.2008
27. O’Donnell DE, Ora J, Webb KA, Laveneziana P, Jensen D. Mechanisms of activity-related dyspnea in pulmonary diseases. Respir Physiol Neurobiol. (2009) 167:116-32. doi: 10.1016/j.resp.2009.01.010

28. Casaburi R, Rennard SI. Exercise limitation in chronic obstructive pulmonary disease. The O'Donnell threshold. Am J Respir Crit Care Med. (2015) 191:873-5. doi: 10.1164/rccm.201501-0084ED

29. Laveneziana P, Webb KA, Ora J, Wadell K, O’Donnell DE. Evolution of dyspnea during exercise in chronic obstructive pulmonary disease: impact of critical volume constraints. Am J Respir Crit Care Med. (2011) 184:1367-73. doi: 10.1164/rccm.201106-1128OC

30. O'Donnell DE, Guenette JA, Maltais F, Webb KA. Decline of resting inspiratory capacity in COPD: the impact on breathing pattern, dyspnea, and ventilatory capacity during exercise. Chest. (2012) 141:753-62. doi: 10.1378/chest.11-0787

31. Neder JA, Berton DC, Marillier M, Bernard AC, O'Donnell DE, Canadian Respiratory Research Network. Inspiratory constraints and ventilatory inefficiency are superior to breathing reserve in the assessment of exertional dyspnea in COPD. COPD. (2019) 16:174-81. doi: 10.1080/15412555.2019.1631776

32. Potter WA, Olafsson S, Hyatt RE. Ventilatory mechanics and expiratory flow limitation during exercise in patients with obstructive lung disease. J Clin Invest. (1971) 50:910-9. doi: 10.1172/JCI106563

33. Stubbing DG, Pengelly LD, Morse JL, Jones NL. Pulmonary mechanics during exercise in subjects with chronic airflow obstruction. J Appl Physiol Respir Environ Exerc Physiol. (1980) 49:511-5. doi: 10.1152/jappl.1980.49.3.511

34. O’Donnell DE, Lam M, Webb KA. Measurement of symptoms, lung hyperinflation, and endurance during exercise in chronic obstructive pulmonary disease. Am J Respir Crit Care Med. (1998) 158(5 Pt 1):1557-65. doi: 10.1164/ajrccm.158.5.9804004

35. O’Donnell DE, Elbehairy AF, Webb KA, Neder JA, Canadian Respiratory Research Network. The link between reduced inspiratory capacity and exercise intolerance in chronic obstructive pulmonary disease. Ann Am Thorac Soc. (2017) 14(Suppl 1):S30-9. doi: 10.1513/AnnalsATS.201610-834FR

36. O'Donnell DE, Revill SM, Webb KA. Dynamic hyperinflation and exercise intolerance in chronic obstructive pulmonary disease. Am J Respir Crit Care Med. (2001) 164:770-7. doi: 10.1164/ajrccm.164.5.2012122

37. O'Donnell DE, Bertley JC, Chau LK, Webb KA. Qualitative aspects of exertional breathlessness in chronic airflow limitation: pathophysiologic mechanisms. Am J Respir Crit Care Med. (1997) 155:109-15. doi: 10.1164/ajrccm.155.1.9001298

38. O'Donnell DE, Hamilton AL, Webb KA. Sensory-mechanical relationships during high-intensity, constant-work-rate exercise in COPD. J Appl Physiol. (1985). (2006) 101:1025-35. doi: 10.1152/japplphysiol.01470.2005

39. Elbehairy AF, Ciavaglia CE, Webb KA, Guenette JA, Jensen D, Mourad SM, et al. Pulmonary gas exchange abnormalities in mild chronic obstructive pulmonary disease. Implications for dyspnea and exercise intolerance. Am J Respir Crit Care Med. (2015) 191:1384-94. doi: 10.1164/rccm.201501-0157OC

40. Elbehairy AF, Guenette JA, Faisal A, Ciavaglia CE, Webb KA, Jensen D, et al. Mechanisms of exertional dyspnoea in symptomatic smokers without COPD. Eur Respir J. (2016) 48:694-705. doi: 10.1183/13993003.00077-2016

41. Ofir D, Laveneziana P, Webb KA, Lam YM, O'Donnell DE. Mechanisms of dyspnea during cycle exercise in symptomatic patients with GOLD stage I chronic obstructive pulmonary disease. Am J Respir Crit Care Med. (2008) 177:622-9. doi: 10.1164/rccm.200707-1064OC

42. Guenette JA, Chin RC, Cheng S, Dominelli PB, Raghavan N, Webb KA, et al. Mechanisms of exercise intolerance in global initiative for chronic obstructive lung disease grade 1 COPD. Eur Respir J. (2014) 44:1177-87. doi: 10.1183/09031936.00034714

43. Schaeffer MR, Ryerson CJ, Ramsook AH, Molgat-Seon Y, Wilkie SS, Dhillon SS, et al. Neurophysiological mechanisms of exertional dyspnoea in fibrotic interstitial lung disease. Eur Respir J. (2018) 51:1701726. doi: 10.1183/13993003.01726-2017

44. Dias OM, Baldi BG, Ferreira JG, Cardenas LZ, Pennati F, Salito C, et al. Mechanisms of exercise limitation in patients with chronic 
hypersensitivity pneumonitis. ERJ Open Res. (2018) 4:00043-2018. doi: 10.1183/23120541.00043-2018

45. Marciniuk DD, Sridhar G, Clemens RE, Zintel TA, Gallagher CG. Lung volumes and expiratory flow limitation during exercise in interstitial lung disease. J Appl Physiol. (1994) 77:963-73. doi: 10.1152/jappl.1994.77.2.963

46. Ofir D, Laveneziana P, Webb KA, O'Donnell DE. Ventilatory and perceptual responses to cycle exercise in obese women. J Appl Physiol. (2007) 102:221726. doi: 10.1152/japplphysiol.00898.2006

47. Quon BS, Wilkie SS, Ramsook AH, Schaeffer MR, Puyat JH, Wilcox PG, et al. Qualitative dimensions of exertional dyspnea in adults with cystic fibrosis. J Appl Physiol. (2016) 121:449-56. doi: 10.1152/japplphysiol.00391.2016

48. Laveneziana P, Garcia G, Joureau B, Nicolas-Jilwan F, Brahimi T, Laviolette L, et al. Dynamic respiratory mechanics and exertional dyspnoea in pulmonary arterial hypertension. Eur Respir J. (2013) 41:578-87. doi: $10.1183 / 09031936.00223611$

49. Yan S, Kaminski D, Sliwinski P. Reliability of inspiratory capacity for estimating end-expiratory lung volume changes during exercise in patients with chronic obstructive pulmonary disease. Am J Respir Crit Care Med. (1997) 156:55-9. doi: 10.1164/ajrccm.156.1.9608113

50. Laveneziana P, Webb KA, Wadell K, Neder JA, O’Donnell DE. Does expiratory muscle activity influence dynamic hyperinflation and exertional dyspnea in COPD? Respir Physiol Neurobiol. (2014) 199:24-33. doi: 10.1016/j.resp.2014.04.005

51. Kyroussis D, Polkey MI, Keilty SE, Mills GH, Hamnegard CH, Moxham $\mathrm{J}$, et al. Exhaustive exercise slows inspiratory muscle relaxation rate in chronic obstructive pulmonary disease. Am J Respir Crit Care Med. (1996) 153:787-93. doi: 10.1164/ajrccm.153.2.8564133

52. O'Donnell DE, Elbehairy AF, Faisal A, Neder JA, Webb KA, Canadian Respiratory Research Network. Sensory-mechanical effects of a dual bronchodilator and its anticholinergic component in COPD. Respir Physiol Neurobiol. (2018) 247:116-25. doi: 10.1016/j.resp.2017.10.001

53. O'Donnell DE, Webb KA. Exertional breathlessness in patients with chronic airflow limitation. The role of lung hyperinflation. Am Rev Respir Dis. (1993) 148:1351-7. doi: $10.1164 /$ ajrccm/148.5.1351

54. Newell SZ, McKenzie DK, Gandevia SC. Inspiratory and skeletal muscle strength and endurance and diaphragmatic activation in patients with chronic airflow limitation. Thorax. (1989) 44:903-12. doi: 10.1136/thx.44.11.903

55. Gandevia SC, McKenzie DK. Activation of the human diaphragm during maximal static efforts. $J$ Physiol. (1985) 367:45-56. doi: 10.1113/jphysiol.1985.sp015813

56. Luo YM, Qiu ZH, Wang Y, He BT, Qin H, Xiao SC, et al. Absence of dynamic hyperinflation during exhaustive exercise in severe COPD reflects submaximal IC maneuvers rather than a nonhyperinflator phenotype. J Appl Physiol. (2020) 128:586-95. doi: 10.1152/japplphysiol.0069 5.2018

57. Graham BL, Steenbruggen I, Miller MR, Barjaktarevic IZ, Cooper BG, Hall GL, et al. Standardization of spirometry 2019 update. An official American Thoracic Society and European Respiratory Society technical statement. Am J Respir Crit Care Med. (2019) 200:e70-88. doi: 10.1164/rccm.201908-1590ST

58. Miller MR, Hankinson J, Brusasco V, Burgos F, Casaburi R, Coates A, et al. Standardisation of spirometry. Eur Respir J. (2005) 26:319-38. doi: 10.1183/09031936.05.00034805

59. O’Donnell DE, Fluge T, Gerken F, Hamilton A, Webb K, Aguilaniu B, et al. Effects of tiotropium on lung hyperinflation, dyspnoea and exercise tolerance in COPD. Eur Respir J. (2004) 23:832-40. doi: 10.1183/09031936.04.00116004

60. O'Donnell DE, Lam M, Webb KA. Spirometric correlates of improvement in exercise performance after anticholinergic therapy in chronic obstructive pulmonary disease. Am J Respir Crit Care Med. (1999) 160:542-9. doi: $10.1164 /$ ajrccm.160.2.9901038

61. Berton DC, Reis M, Siqueira AC, Barroco AC, Takara LS, Bravo DM, et al. Effects of tiotropium and formoterol on dynamic hyperinflation and exercise endurance in COPD. Respir Med. (2010) 104:1288-96. doi: 10.1016/j.rmed.2010.05.017

62. Belman MJ, Botnick WC, Shin JW. Inhaled bronchodilators reduce dynamic hyperinflation during exercise in patients with chronic obstructive pulmonary disease. Am J Respir Crit Care Med. (1996) 153:967-75. doi: $10.1164 /$ ajrccm.153.3.8630581

63. Hsia D, Casaburi R, Pradhan A, Torres E, Porszasz J. Physiological responses to linear treadmill and cycle ergometer exercise in COPD. Eur Respir J. (2009) 34:605-15. doi: 10.1183/09031936.00069408

64. Puente-Maestu L. Physiological rationale of commonly used clinical exercise tests. Pulmonology. (2020) 26:159-65. doi: 10.1016/j.pulmoe.2019.10.004

65. Dolmage TE, Goldstein RS. Repeatability of inspiratory capacity during incremental exercise in patients with severe COPD. Chest. (2002) 121:70814. doi: $10.1378 /$ chest.121.3.708

66. O'Donnell DE, Travers J, Webb KA, He Z, Lam YM, Hamilton A, et al. Reliability of ventilatory parameters during cycle ergometry in multicentre trials in COPD. Eur Respir J. (2009) 34:866-74. doi: 10.1183/09031936.00168708

67. Puente-Maestu L, Palange P, Casaburi R, Laveneziana P, Maltais F, Neder $\mathrm{JA}$, et al. Use of exercise testing in the evaluation of interventional efficacy: an official ERS statement. Eur Respir J. (2016) 47:429-60. doi: $10.1183 / 13993003.00745-2015$

68. Casanova C, Cote C, de Torres JP, Aguirre-Jaime A, Marin JM, Pinto-Plata V, et al. Inspiratory-to-total lung capacity ratio predicts mortality in patients with chronic obstructive pulmonary disease. Am J Respir Crit Care Med. (2005) 171:591-7. doi: 10.1164/rccm.200407-867OC

69. Marin JM, Carrizo SJ, Gascon M, Sanchez A, Gallego B, Celli BR. Inspiratory capacity, dynamic hyperinflation, breathlessness, and exercise performance during the 6-minute-walk test in chronic obstructive pulmonary disease. Am J Respir Crit Care Med. (2001) 163:1395-9. doi: 10.1164 /ajrccm.163.6.2003172

70. Tantucci C, Donati P, Nicosia F, Bertella E, Redolfi S, De Vecchi $\mathrm{M}$, et al. Inspiratory capacity predicts mortality in patients with chronic obstructive pulmonary disease. Respir Med. (2008) 102:613-9. doi: 10.1016/j.rmed.2007.11.004

71. Zaman M, Mahmood S, Altayeh A. Low inspiratory capacity to total lung capacity ratio is a risk factor for chronic obstructive pulmonary disease exacerbation. Am J Med Sci. (2010) 339:411-4. doi: 10.1097/MAJ.0b013e3181d6578c

72. Ozgur ES, Nayci SA, Ozge C, Tasdelen B. An integrated index combined by dynamic hyperinflation and exercise capacity in the prediction of morbidity and mortality in COPD. Respir Care. (2012) 57:1452-9. doi: 10.4187/respcare.01440

73. Beeh KM, Korn S, Beier J, Jadayel D, Henley M, D'Andrea P, et al. Effect of QVA149 on lung volumes and exercise tolerance in COPD patients: the BRIGHT study. Respir Med. (2014) 108:584-92. doi: 10.1016/j.rmed.2014.01.006

74. Beeh KM, Wagner F, Khindri S, Drollmann AF. Effect of indacaterol on dynamic lung hyperinflation and breathlessness in hyperinflated patients with COPD. COPD. (2011) 8:340-5. doi: 10.3109/15412555.2011.594464

75. Maltais F, Hamilton A, Marciniuk D, Hernandez P, Sciurba FC, Richter K, et al. Improvements in symptom-limited exercise performance over $8 \mathrm{~h}$ with once-daily tiotropium in patients with COPD. Chest. (2005) 128:1168-78. doi: $10.1378 /$ chest.128.3.1168

76. O'Donnell DE, Voduc N, Fitzpatrick M, Webb KA. Effect of salmeterol on the ventilatory response to exercise in chronic obstructive pulmonary disease. Eur Respir J. (2004) 24:86-94. doi: 10.1183/09031936.04.00072703

77. Maltais F, Celli B, Casaburi R, Porszasz J, Jarreta D, Seoane B, et al. Aclidinium bromide improves exercise endurance and lung hyperinflation in patients with moderate to severe COPD. Respir Med. (2011) 105:580-7. doi: 10.1016/j.rmed.2010.11.019

78. Man WD, Mustfa N, Nikoletou D, Kaul S, Hart N, Rafferty GF, et al. Effect of salmeterol on respiratory muscle activity during exercise in poorly reversible COPD. Thorax. (2004) 59:471-6. doi: 10.1136/thx.2003.019620

79. Neder JA, Fuld JP, Overend T, Thirlwell J, Carter R, Stevenson R, et al. Effects of formoterol on exercise tolerance in severely disabled patients with COPD. Respir Med. (2007) 101:2056-64. doi: 10.1016/j.rmed.2007.06.006

80. O’Donnell DE, Sciurba F, Celli B, Mahler DA, Webb KA, Kalberg CJ, et al. Effect of fluticasone propionate/salmeterol on lung hyperinflation and exercise endurance in COPD. Chest. (2006) 130:647-56. doi: 10.1378/chest.130.3.647 
81. Worth H, Forster K, Eriksson G, Nihlen U, Peterson S, Magnussen H. Budesonide added to formoterol contributes to improved exercise tolerance in patients with COPD. Respir Med. (2010) 104:1450-9. doi: 10.1016/j.rmed.2010.07.006

82. Beeh KM, Singh D, Di Scala L, Drollmann A. Once-daily NVA237 improves exercise tolerance from the first dose in patients with COPD: the GLOW3 trial. Int J Chron Obstruct Pulmon Dis. (2012) 7:503-13. doi: 10.2147/COPD.S32451

83. O’Donnell DE, Casaburi R, Vincken W, Puente-Maestu L, Swales J, Lawrence $\mathrm{D}$, et al. Effect of indacaterol on exercise endurance and lung hyperinflation in COPD. Respir Med. (2011) 105:1030-6. doi: 10.1016/j.rmed.2011.03.014

84. Somfay A, Porszasz J, Lee SM, Casaburi R. Dose-response effect of oxygen on hyperinflation and exercise endurance in nonhypoxaemic COPD patients. Eur Respir J. (2001) 18:77-84. doi: 10.1183/09031936.01.00082201

85. Peters MM, Webb KA, O'Donnell DE. Combined physiological effects of bronchodilators and hyperoxia on exertional dyspnoea in normoxic COPD. Thorax. (2006) 61:559-67. doi: 10.1136/thx.2005.053470

86. Casaburi R, Patessio A, Ioli F, Zanaboni S, Donner CF, Wasserman K. Reductions in exercise lactic acidosis and ventilation as a result of exercise training in patients with obstructive lung disease. Am Rev Respir Dis. (1991) 143:9-18. doi: 10.1164/ajrccm/143.1.9

87. Maltais F, LeBlanc P, Jobin J, Berube C, Bruneau J, Carrier L, et al. Intensity of training and physiologic adaptation in patients with chronic obstructive pulmonary disease. Am J Respir Crit Care Med. (1997) 155:55561. doi: 10.1164/ajrccm.155.2.9032194

88. O’Donnell DE, McGuire M, Samis L, Webb KA. General exercise training improves ventilatory and peripheral muscle strength and endurance in chronic airflow limitation. Am J Respir Crit Care Med. (1998) 157(5 Pt 1):1489-97. doi: 10.1164/ajrccm.157.5.9708010

89. Porszasz J, Emtner M, Goto S, Somfay A, Whipp BJ, Casaburi R. Exercise training decreases ventilatory requirements and exercise-induced hyperinflation at submaximal intensities in patients with COPD. Chest. (2005) 128:2025-34. doi: 10.1378/chest.128.4.2025

90. Puente-Maestu L, Abad YM, Pedraza F, Sanchez G, Stringer WW. A controlled trial of the effects of leg training on breathing pattern and dynamic hyperinflation in severe COPD. Lung. (2006) 184:159-67. doi: 10.1007/s00408-005-2576-x

91. Dowman L, Hill CJ, Holland AE. Pulmonary rehabilitation for interstitial lung disease. Cochrane Database Syst Rev. (2014) 2014:CD006322. doi: 10.1002/14651858.CD006322.pub3

92. Holland AE, Hill CJ, Conron M, Munro P, McDonald CF. Short term improvement in exercise capacity and symptoms following exercise training in interstitial lung disease. Thorax. (2008) 63:549-54. doi: 10.1136/thx.2007.088070

93. Huppmann P, Sczepanski B, Boensch M, Winterkamp S, Schonheit-Kenn U, Neurohr C, et al. Effects of inpatient pulmonary rehabilitation in patients with interstitial lung disease. Eur Respir J. (2013) 42:444-53. doi: 10.1183/09031936.00081512

94. Ryerson CJ, Camp PG, Eves ND, Schaeffer M, Syed N, Dhillon S, et al. High oxygen delivery to preserve exercise capacity in patients with idiopathic pulmonary fibrosis treated with nintedanib. Methodology of the HOPE-IPF study. Ann Am Thorac Soc. (2016) 13:1640-7. doi: 10.1513/AnnalsATS.201604-267OC

95. Ryerson CJ, Cayou C, Topp F, Hilling L, Camp PG, Wilcox PG, et al. Pulmonary rehabilitation improves long-term outcomes in interstitial lung disease: a prospective cohort study. Respir Med. (2014) 108:203-10. doi: 10.1016/j.rmed.2013.11.016

96. Eves ND, Petersen SR, Haykowsky MJ, Wong EY, Jones RL. Heliumhyperoxia, exercise, and respiratory mechanics in chronic obstructive pulmonary disease. Am J Respir Crit Care Med. (2006) 174:763-71. doi: 10.1164/rccm.200509-1533OC

97. Laveneziana P, Valli G, Onorati P, Paoletti P, Ferrazza AM, Palange P. Effect of heliox on heart rate kinetics and dynamic hyperinflation during high-intensity exercise in COPD. Eur J Appl Physiol. (2011) 111:225-34. doi: 10.1007/s00421-010-1643-Z

98. Palange P, Valli G, Onorati P, Antonucci R, Paoletti P, Rosato A, et al. Effect of heliox on lung dynamic hyperinflation, dyspnea, and exercise endurance capacity in COPD patients. J Appl Physiol. (2004) 97:1637-42. doi: 10.1152/japplphysiol.01207.2003

99. Lammi MR, Ciccolella D, Marchetti N, Kohler M, Criner GJ. Increased oxygen pulse after lung volume reduction surgery is associated with reduced dynamic hyperinflation. Eur Respir J. (2012) 40:837-43. doi: 10.1183/09031936.00169311

100. Martinez FJ, de Oca MM, Whyte RI, Stetz J, Gay SE, Celli BR. Lung-volume reduction improves dyspnea, dynamic hyperinflation, and respiratory muscle function. Am $J$ Respir Crit Care Med. (1997) 155:1984-90. doi: 10.1164/ajrccm.155.6. 9196106

101. O’Donnell DE, Webb KA, Bertley JC, Chau LK, Conlan AA. Mechanisms of relief of exertional breathlessness following unilateral bullectomy and lung volume reduction surgery in emphysema. Chest. (1996) 110:18-27. doi: $10.1378 /$ chest.110.1.18

Conflict of Interest: DO'D has received research funding via Queen's University from Canadian Institutes of Health Research, Canadian Respiratory Research Network, AstraZeneca, and Boehringer Ingelheim and has served on speaker bureaus, consultation panels, and advisory boards for AstraZeneca and Boehringer Ingelheim.

The remaining authors declare that the research was conducted in the absence of any commercial or financial relationships that could be construed as a potential conflict of interest.

Copyright (C) 2020 Milne, Domnik, Phillips, James, Vincent, Neder and O'Donnell. This is an open-access article distributed under the terms of the Creative Commons Attribution License (CC BY). The use, distribution or reproduction in other forums is permitted, provided the original author(s) and the copyright owner(s) are credited and that the original publication in this journal is cited, in accordance with accepted academic practice. No use, distribution or reproduction is permitted which does not comply with these terms. 